\title{
Dual effect of Lutzomyia longipalpis saliva on Leishmania braziliensis infection is mediated by distinct saliva-induced cellular recruitment into $\mathrm{BALB} / \mathrm{c}$ mice ear
}

Vanessa Carregaro', Diego Luis Costa' ${ }^{1}$, Claudia Brodskynn ${ }^{3,4,5}$, Aldina Maria Barral ${ }^{3,4,5}$, Manuel Barral-Netto ${ }^{3,4,5}$, Fernando Q Cunha ${ }^{1,2}$ and João Santana Silva ${ }^{1 *}$

\begin{abstract}
Background: Leishmania parasites are transmitted to their vertebrate hosts by infected Phlebotomine sand flies during the blood meal of the flies. Sand fly saliva is known to enhance Leishmania spp. infection, while preexposure to saliva protects mice against parasitic infections. In this study, we investigated the initial inflammatory leucocyte composition induced by one or three inocula of salivary gland extract (SGE) from Lutzomyia longipalpis in the presence or absence of Leishmania braziliensis.

Results: We demonstrated that inoculating SGE once (SGE-1X) or three times (SGE-3X), which represented a coinoculation or a pre-exposure to saliva, respectively, resulted in different cellular infiltrate profiles. Whereas SGE-1X led to the recruitment of all leucocytes subtypes including $\mathrm{CD} 4^{+} \mathrm{T}$ cells, $\mathrm{CD} 4^{+} \mathrm{CD} 25^{+} \mathrm{T}$ cells, dendritic cells, macrophages and neutrophils, the immune cell profile in the SGE-3X group differed dramatically, as CD4 ${ }^{+} T$ cells, $\mathrm{CD}^{+} \mathrm{CD} 25^{+} \mathrm{T}$ cells, dendritic cells, macrophages and neutrophils were decreased and $\mathrm{CD} 8^{+} \mathrm{T}$ cells were increased. The SGE-1X group did not show differences in the ear lesion size; however, the SGE-1X group harbored a higher number of parasites. On the other hand, the SGE-3X group demonstrated a protective effect against parasitic disease, as the parasite burden was lower even in the earlier stages of the infection, a period in which the SGE-1X group presented with larger and more severe lesions. These effects were also reflected in the cytokine profiles of both groups. Whereas the SGE-1X group presented with a substantial increase in IL-10 production, the SGE-3X group showed an increase in IFN- $\gamma$ production in the draining lymph nodes. Analysis of the inflammatory cell populations present within the ear lesions, the SGE-1X group showed an increase in $\mathrm{CD}^{+} \mathrm{FOXP3}^{+}$cells, whereas the $\mathrm{CD}^{+}{ }^{+} \mathrm{FOXP} 3^{+}$population was reduced in the SGE-3X group. Moreover, $\mathrm{CD} 4^{+} \mathrm{T}$ cells and $\mathrm{CD} 8^{+} \mathrm{T}$ cells producing IFN- $\gamma$ were highly detected in the ears of the SGE-3X mice prior to infection. In addition, upon treatment of SGE-3X mice with anti-IFN- $\gamma$ monoclonal antibody, we observed a decrease in the protective effect of SGE-3X against L. braziliensis infection.
\end{abstract}

Conclusions: These results indicate that different inocula of Lutzomyia longipalpis salivary gland extract can markedly modify the cellular immune response, which is reflected in the pattern of susceptibility or resistance to Leishmania braziliensis infection.

Keywords: Phlebotomines saliva, Lutzomyia longipalpis saliva, Leishmania braziliensis, Inflammatory leucocytes, Cytokines, Immunoregulation

\footnotetext{
* Correspondence: jsdsilva@fmrp.usp.br

'Department of Biochemistry and Immunology, School of Medicine of

Ribeirão Preto, University of São Paulo, Av Bandeirantes, 3900. Ribeirão Preto,

São Paulo, Brazil

Full list of author information is available at the end of the article
} 


\section{Background}

Leishmaniasis is a vector-borne disease transmitted exclusively by sand fly bites [1], during which the host is inoculated with saliva. The saliva has been shown to downregulate the immune response allowing the establishment of successful pathogen infection [2-4]. Co-injection of Leishmania and salivary gland homogenates from either Lutzomyia longipalpis or Phlebotomus papatasi in naïve mice produces a substantial increase in lesion size and parasite burden. The increase in infectivity was associated with the capacity of the saliva to selectively inhibit antigen presentation and nitric oxide (NO) and hydrogen peroxide production thus inhibiting the ability of macrophages to kill the intracellular parasites [5,6]. Furthermore, Leishmania vector saliva inhibits the production of protective type 1 cytokines such IL-12 and IFN- $\gamma$ [7-9], while enhancing the production of interleukin (IL)-10, IL-4, IL-6 and prostaglandin $\mathrm{E}(\mathrm{PGE})_{2}$, all of which enhance parasite survival [10-13].

Pre-exposure to saliva or bites from uninfected sand flies can lead to an increase in host resistance to Leishmania as a consequence of developing a long-term humoral immune response against the salivary components responsible for pathogen establishment [14]. However, the saliva-induced protection was associated with a delayed-type hypersensitivity (DTH) response and the upregulation of IFN- $\gamma$ and IL-12 at the site of inoculation [15]. Vaccinating mice against Maxidilan (MAX), the potent salivary vasodilatador from Lutzomyia longipalpis sand fly, protected the animal from $L$. major infection by eliciting anti-MAX antibodies and a Th1 immune response [14]. Moreover, mice inoculated with a $15-\mathrm{kDa}$ salivary protein (PpSP15) produced a strong DTH response, which even occurred in B cell knockout mice, suggesting that the cellular immune response against the saliva provided most, if not all, of the protective effect [16]. However, the mechanism responsible for the salivainduced dual immunity observed in Leishmania infections remains unknown.

Cell recruitment is a vital event during inflammation. The cell number and cellular composition soon after an inflammatory stimulus is encountered greatly influences the future responses and the development of an adaptive immune response. Leukocyte recruitment to infected tissue is a crucial event for the control of infections such as leishmaniasis $[17,18]$. Furthermore, clinical leishmaniasis lesions are associated with an influx of inflammatory cells [19].

Sand fly saliva contains a mixture of pharmacologically active compounds that influence leucocyte migration. Phlebotomus dubosqi saliva attracts vertebrate monocytes in vitro [20] and P. papatasi saliva attracts macrophages and enhances infections by Leishmania donovani resulting in an increased parasitic load [21]. Lutzomyia longipalpis and P. papatasi saliva recruit eosinophils and macrophages through the release of Th2 cytokines and chemokines $[13,17,18]$. Neutrophils are recruited to the site of Leishmania inoculation during the bite of an infected sand fly and prevent parasite surveillance via oxidant- and protease-dependent mechanisms [22]. The co-injection of L. major with Lutzomyia longipalpis saliva increases the number of $\mathrm{CD} 4^{+} \mathrm{CD} 45 \mathrm{RB}^{\text {low }} \mathrm{T}$ cells within the inoculation site. Undoubtedly, sand fly saliva directly influences the recruitment of leucocytes by altering the adaptive immune response. In the current study, we characterized the distinct cellular composition within BALB/c mouse ears following the inoculation of salivary gland extract (SGE) from Lutzomyia longipalpis in association with distinct patterns of resistance or susceptibility to L. braziliensis infection.

\section{Methods}

Mice

Male BALB/c mice weighing 18-22 g were housed in temperature-controlled rooms $\left(22-25^{\circ} \mathrm{C}\right)$ with ad libitum access to water and food in the animal facility of the Department of Immunology, School of Medicine of Ribeirão Preto, University of São Paulo (Brazil). All experiments were conducted in accordance with $\mathrm{NIH}$ guidelines on the welfare of experimental animals, and all experiments were approved by the Ribeirão Preto School of Medicine Ethics Committee.

\section{Salivary gland extract (SGE)}

SGE was prepared from 7- to 10-day-old laboratory-bred, female Lutzomyia longipalpis as previously described [23]. Briefly, 50 pairs of salivary glands were dissected under sterile conditions in endotoxin-free PBS, placed in $50 \mu \mathrm{l}$ of PBS and were kept at $-70^{\circ} \mathrm{C}$ until use. Immediately before use, the glands were disrupted by sonication using a Sonifer 450 homogenizer (Branson, Danbury, Connecticut). Endotoxin levels were evaluated by using the QCL1000(r) Chromogenic LAL Endpoint Assay kit (Lonza, Switzerland), which revealed negligible levels of endotoxin within the salivary gland supernatants.

\section{SGE intradermal inoculation}

The ear dermis of BALB/c mice was intradermally inoculated with different inoculums of SGE (SGE-1X and SGE-3X). Each inoculum consisted of 0.5 pair of SGE diluted in $10 \mu \mathrm{L}$ of PBS /ear. SGE-1X group received one single inoculum of SGE and, other group, the mice received SGE-1X plus promastigote forms of L. braziliensis $\left(1 \times 10^{5}\right)$. The protocol of immunization with saliva consisted of three inoculums of SGE, with intervals of 10 days among each ones. Alternatively, the mice received three inoculums of SGE being that, in the third one, they also received the infection with parasites. The 
control group, the mice received one injection with $10 \mathrm{uL}$ of PBS. Thus, the groups are: Group PBS = one injection of PBS; Group SGE-1X = one injection of SGE; Group SGE-3X = three injections of SGE; Group PBS/ parasite $=$ PBS plus parasite; Group SGE-1X/parasite = SGE-1X plus parasite; Group SGE-3X/parasite = SGE $2 \mathrm{X}+\mathrm{SGE}-1 \mathrm{X}$ plus parasite.

\section{Parasitic, intradermal infection and parasitic burden quantification}

L. braziliensis was cultured in Schneider (Sigma, Saint Louis, MO, USA) medium supplemented with 20\% heatinactivated fetal calf serum (Cultilab, Campinas, SP, Brazil), $4 \mathrm{mM} \mathrm{NaHCO}$, $100 \mathrm{U} / \mathrm{ml}$ penicillin, $100 \mu \mathrm{g} / \mathrm{ml}$ streptomycin (all from Gibco, Grand Island, NY, USA), and $2 \% \mathrm{v} / \mathrm{v}$ male human urine at $25^{\circ} \mathrm{C}$. Promastigotes of L. braziliensis were isolated from stationary phase cultures (5-6th day of culture), centrifuged at $1540 \mathrm{~g}$ at $4^{\circ} \mathrm{C}$ for $10 \mathrm{~min}$ and washed in PBS. Promastigotes of $L$. braziliensis were isolated from stationary phase cultures (5-6th day of culture), centrifuged at $1540 \times \mathrm{g}$ at $4^{\circ} \mathrm{C}$ for $10 \mathrm{~min}$ and washed in PBS. The L. braziliensis promastigotes $\left(1 \times 10^{5}\right)$ were inoculated intradermally into the ear of mice previously inoculated with SGE $(-1 \mathrm{X}$ or $-3 \mathrm{X})$ or vehicle (PBS) using a $27.5-\mathrm{G}$ needle in a total volume of $10 \mu \mathrm{l}$. The development of lesions was monitored by measuring the diameter of the ear lesion with a vernier caliper. To quantify the parasitic burden, the dermal sheets of the infected ears were separated, deposited dermal side down, and then homogenized using a Medimachine (Becton \& Dickinson Biosciences, San Diego, CA, USA) tissue grinder in a microfuge tube containing $1000 \mu \mathrm{l}$ of supplemented Schneider medium (Sigma, Saint Louis, MO, USA) for $4 \mathrm{~min}$. The tissue homogenates were serially diluted in 96-well flat-bottom microtiter plates (Corning Incorporated, NY, USA) containing biphasic medium prepared using $50 \mu \mathrm{l}$ of NNN medium with $30 \%$ of defibrinated rabbit blood and were overlaid with $100 \mu \mathrm{l}$ of Schneider medium (Sigma). The number of viable parasites in each tissue was determined from the highest dilution at which promastigotes could be grown after 7 days of incubation at $26^{\circ} \mathrm{C}$.

\section{Leucocyte isolation from lesions}

To characterize the leucocytes within the inoculation site, the inflammatory cells were recovered as previously described [24]. Briefly, at different time points after intradermal inoculation, ears were collected and incubated at $37^{\circ} \mathrm{C}$ for one hour in RPMI-1640 medium containing $2 \mathrm{mM}$ L-glutamine, $100 \mathrm{U} / \mathrm{ml}$ penicillin, $100 \mu \mathrm{g} / \mathrm{ml}$ streptomycin (all from Gibco, Grand Island, NY, USA) and $500 \mu \mathrm{g} / \mathrm{ml}$ Liberase CI (Roche, Basel, Switzerland). The tissues were processed inside Medcons using a Medimachine (both from BD Biosciences). After processing, the cells were filtered through a $50-\mu \mathrm{m}$ filter, viability was assessed by trypan blue exclusion, and the cell concentration was determined.

\section{Flow cytometry}

The dermal inflammatory cells were gated based on their characteristic size (FSC) and granularity (SSC), and the $\mathrm{T}$ lymphocytes $\left(\mathrm{CD} 4^{+} \mathrm{CD}^{+}, \mathrm{CD}^{+} \mathrm{CD}^{+}\right.$and $\left.\mathrm{CD} 4{ }^{+} \mathrm{CD} 25^{+}\right)$ dendritic cells $\left(\mathrm{CD} 11 \mathrm{c}^{+} \mathrm{CD} 11 \mathrm{~b}^{+} \mathrm{MHC}-\mathrm{II}^{+}\right)$, macrophages $\left(\mathrm{F} 4 / 80^{+} \mathrm{CD} 11 \mathrm{c}^{-} \mathrm{MHC}-\mathrm{II}^{+}\right)$and neutrophils $\left(\mathrm{Gr} 1^{+} \mathrm{MHC}^{-\mathrm{II}^{-}}\right)$ (BD Biosciences) were identified individually. The isotype controls used were rat IgG2b and rat IgG2a. For regulatory $\mathrm{T}$ cell phenotyping, $\mathrm{CD} 4{ }^{+} \mathrm{CD} 25^{+} \mathrm{T}$ cells were stained with anti-FoxP3 antibody conjugated to phycoeritrin (PE) (e-Biosciences). For intracellular staining, the cells were permeabilized using a Cytofix/Cytoperm kit (BD Biosciences) according to the manufacturer's instructions. For all analyses, the results were compared with the results obtained from cells stained with isotype control antibodies. Cell acquisition was performed using a FACSort flow cytometer. Data were plotted and analyzed using Cell Quest (BD Biosciences) and FlowJo software (Tree Star, Ashland, OR).

\section{Cytokine release}

To assess the influence of SGE on cytokine production, single-cell suspensions of the draining retromaxillar lymph nodes from the SGE-1X-, SGE-3X- or PBSinoculated mice were prepared aseptically, diluted to a concentration of $2 \times 10^{6}$ cells $/ \mathrm{ml}$, and dispensed into 48well plates in a total volume of $500 \mu \mathrm{l}$ of complete RPMI-1640 medium with or without $5 \times 10^{6}$ live stationary phase L. braziliensis promastigotes. Cell culture supernatants were harvested after 72 hours of culture at $37^{\circ} \mathrm{C}$ in $5 \% \mathrm{CO}_{2}$, and the levels of IFN- $\gamma$ (BD Biosciences) and IL-10 (R\&D Systems Minneapolis, MN, USA) were determined by using commercial ELISA kits, according to the manufacturer's instructions.

\section{In vivo depletion of IFN- $\gamma$ cytokine}

R46A2 hybridoma cells secreting rat IgG1 anti-IFN- $\gamma$ were used in this study. These cells were grown as ascites in pristine (Sigma)-primed, nude-backcrossed BALB/c mice. R46A2 antibodies were purified from ascitic fluid as described elsewhere [25]. Groups of SGE-3X-inoculated $\mathrm{BALB} / \mathrm{c}$ mice were given $500 \mu \mathrm{g}$ of R46A2 mAb or normal rat IgG control antibody intraperitoneally 1 day before infection with L. braziliensis (day 1) and were given $250 \mu \mathrm{g}$ of the respective antibody every 3 days for 3 weeks thereafter.

\section{Statistical analyses}

The data are reported as the mean \pm SEM and are representative of two or three independent experiments. The 
means between different groups were compared by the analysis of variance (ANOVA) followed by the Tukey test for unpaired values. $\mathrm{P}<0.05$ was considered to be statistically significant.

\section{Results}

Kinetics of the SGE effect in the recruitment of leucocytes to the site of inoculation in BALB/c mice

We analyzed the accumulation of leukocytes in the dermis after $0,6,12,24$ and 48 hours post-intradermal inoculation of Lutzomyia longipalpis salivary gland extract (SGE) (0.5 pair of glands/mouse) into the ears of BALB/c mice. SGE induced neutrophils $\left(\mathrm{GR} 1^{+} \mathrm{MHC}-\mathrm{II}^{-}\right)$cell recruitment 6 hours post-inoculation, which persisted for 48 hours. $\mathrm{CD}^{+} \mathrm{T}$ cells, $\mathrm{CD} 8^{+} \mathrm{T}$ cells and $\mathrm{CD} 4^{+} \mathrm{CD} 25^{+}$ $\mathrm{T}$ cells appeared 12 hours post-inoculation and persisted during all period analyzed. Macrophages (F4/80 ${ }^{+} \mathrm{CD} 11 \mathrm{c}^{-}$ $\mathrm{MHC}-\mathrm{II}^{+}$) cell accumulation was observed 12 hours after inoculation, and dendritic cells $\left(\mathrm{CD} 11 \mathrm{~b}^{+} \mathrm{CD} 11 \mathrm{c}^{+} \mathrm{MHC}-\mathrm{II}^{+}\right)$ levels did not change (Figure 1A).

To determine that the leukocyte migration is SGEspecific and not due damage inflicted by the needle injection, the kinect of leucocyte migration after similar amounts of PBS $(10 \mu \mathrm{L})$ inoculated into ears of mice was performed. As showed, the amounts of dendritic cells, neutrophils, macrophages in PBS-inoculated mice was similar in all time points analyzed and was comparable that those recovered from naïve ears mice (Figure 1B), confirming the specificity of SGE in the leukocyte recruitment.

\section{Inflammatory infiltrate after one or three inocula of SGE}

Next, we determined whether saliva promotes or protects against leishmaniasis. First, we compared the inflammatory infiltrate after different injections of SGE. BALB/c mice received one or three intradermal ear injections of SGE, and the emigrated leucocytes were analyzed. As a control group, BALB/c mice were inoculated with PBS (time 0). Our results show that the SGE-1X group had an increased recruitment of different subtypes analyzed: $\mathrm{CD}^{+}{ }^{+} \mathrm{T}$ cells, $\mathrm{CD}^{+} \mathrm{T}$ cells, $\mathrm{CD} 4^{+} \mathrm{CD} 25^{+}$cells, macrophage and neutrophil (Figure 2). The leukocyte influx into the ears of mice from the SGE-3X group consisted of CD4 ${ }^{+} \mathrm{T}$ cells, CD ${ }^{+} \mathrm{CD} 25^{+} \mathrm{T}$ cells, macrophage and neutrophil, which showed 53, 84, 71 and 53\% reductions, respectively, relative to the amount of cells in the ears of mice from the SGE-1X. In contrast, the amount of $\mathrm{CD}^{+} \mathrm{T}$ cells that migrated to the ear of the SGE-3X group was $70 \%$ higher than the SGE-1X group (Figure 2B). Regarding to dendritic cells, there was no difference among all groups analyzed (Figure 2D). Therefore, pre-exposure of saliva leads to changes in the pattern of leukocyte migration to the site of inoculation.

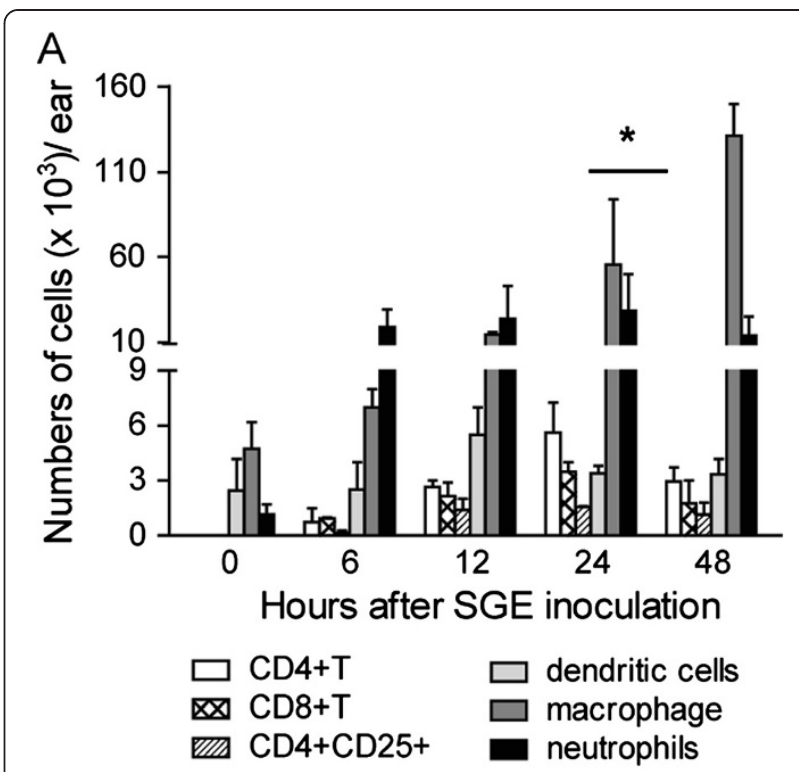

B

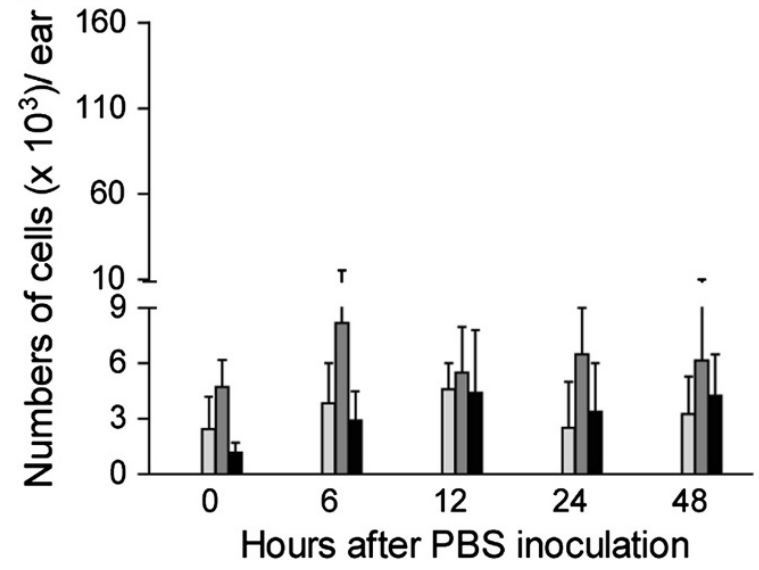

Figure 1 Kinetics of the inflammatory infiltrate induced by Lutzomyia longipalpis saliva at the site of inoculation. BALB/C mice were inoculated intradermally within the ear dermis with half of the salivary gland extract (SGE) generated from the two salivary glands diluted in $10 \mu$ of PBS (A) or a injection with PBS only (B). The leucocytes from three mouse ears/group were obtained at $0,6,12,24$ and $48 \mathrm{~h}$ after inoculation, and different populations were identified using flow cytometry. The data showed represent the mean \pm SEM and are representative of three independent experiments $(n=3)$. ${ }^{*} P<0.05$ compared to 0 hours (naive).

The effect of different SGE doses on the course of $L$. braziliensis infection

Next, we evaluated whether pre-exposure to saliva interferes with the course of $L$. braziliensis infections. To this end, $1 \times 10^{5}$ L. braziliensis stationary phase promastigote forms suspended in PBS or SGE were inoculated into $\mathrm{BALB} / \mathrm{c}$ mice ear pretreated with $\mathrm{PBS}-2 \mathrm{X}$ or SGE-2X. The development of the lesion was monitored weekly by measuring the diameter of the infected ear with a vernier caliper and comparing it with the non-infected ear on the same mouse. Mice challenged with the parasite in 

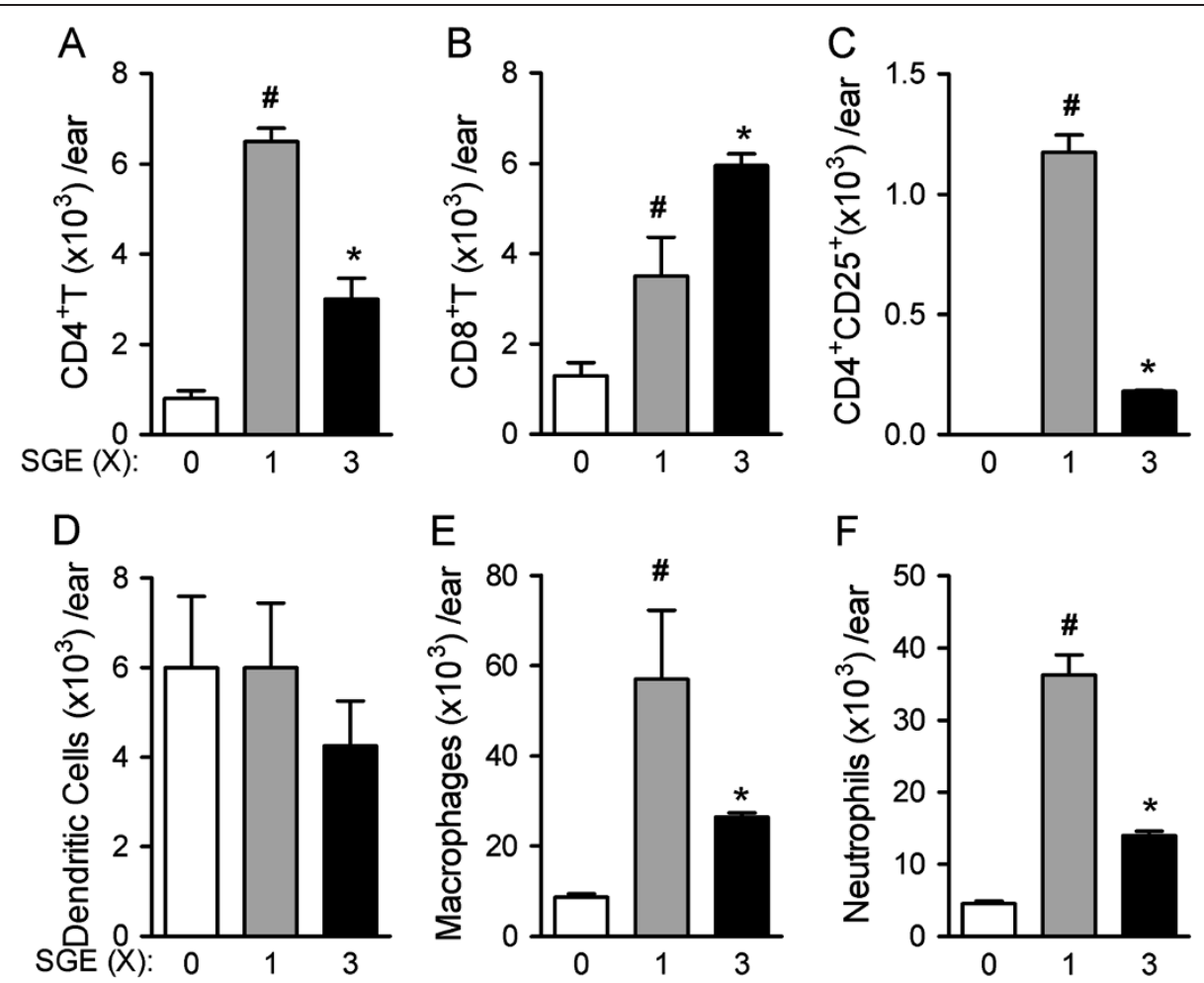

Figure 2 Comparative analyses of the inflammatory infiltrate into the site of infection after SGE inoculation. BALB/C mice were inoculated i.d. once (SGE-1X-gray bars) or three times (SGE-3X-black bars) within the ear dermis with SGE (derived from 0.5 pair of salivary glands diluted in $10 \mu \mathrm{l}$ of PBS/ear) or PBS (10 $\mu$ l/ear-white bars). The mice were euthanized $24 \mathrm{~h}$ later, and ears were harvested for inflammatory infiltrate characterization. The total number of $C D 4^{+} T$ cells (A), CD8 ${ }^{+} T$ cells (B), $C D 4^{+} C D 25^{+}$cells (C); dendritic cells (D), macrophages (E) and neutrophils (F) present within the ears were identified by flow cytometry. Data represent the mean \pm SEM and are representative of three independent experiments $(n=4) .{ }^{\#} P<0.05$ compared with PBS (control group). ${ }^{*} P<0.05$ compared with the SGE- 1 X group.

the presence of SGE-1X or PBS showed an increased in the lesion beginning on the 3rd week and continued to progress until the 5 th week of infection $(\mathrm{p}<0.05)$ (Figure 3A). After the 5th week, we observed a decrease in the ear size until the 7th week. Despite similar rates of edema in both groups (SGE-1X and PBS), mice that received SGE-1X showed higher parasite titers in the ear at the 3rd and 7th week post-infection when compared with mice inoculated with parasites in PBS (Figure 3B). Conversely, mice pretreated with saliva $2 \mathrm{X}$ and challenged with SGE plus parasite, referred to as SGE-3X, did not exhibit edema until the 7th week of infection. Furthermore, significantly lower numbers of parasites were detected on the 3rd and 7th week post-infection in mice that received SGE-3X when compared with mice that received parasite in SGE-1X (Figure 3B). In summary, our results are consistent with previous studies, which have shown that pre-exposure to saliva results in the protection against infection.

Furthermore, we analyzed the ability of the draining lymph node cells from SGE-1X-, SGE-3X- or PBSinoculated mice at the 7th week post-infection to produce IL-10 and IFN- $\gamma$ in an attempt to understand the mechanism by which saliva exacerbates or protect mice against parasitic infection. Our results showed that the total lymph node cells from SGE-1X-inoculated mice produced more IL-10 after stimulation in vitro with parasitic antigen relative to mice inoculated with PBS or SGE-3X (Figure 4A). On the contrary, SGE-3X-treated mice produced significantly increased levels of IFN- $\gamma$ when compared with the other groups of infected mice (Figure 4B).

The cells that migrated to the site of parasite inoculation were identified by flow cytometry. As shown in Figure 5, L. braziliensis infection induced the recruitment of T lymphocytes such as $\mathrm{CD}^{+}{ }^{+} \mathrm{T}$ and $\mathrm{CD}^{+} \mathrm{T}$. Likewise, both populations were detected in the ears of SGE-1X-inoculated mice. In addition, similar numbers of $\mathrm{CD} 4^{+} \mathrm{T}$ cells and $\mathrm{CD}^{+} \mathrm{T}$ cells producing IFN- $\gamma$ ex vivo were found in both the SGE-1X and the PBS group. By comparison, the leukocyte influx was altered in the ears of SGE-3X-inoculated mice. SGE-3X markedly increased the numbers of $\mathrm{CD}^{+} \mathrm{T}$ and $\mathrm{CD}^{+} \mathrm{T}$ cells by two- to three-fold when compared with the SGE-1X group. Furthermore, the production of IFN- $\gamma$ by both T lymphocyte populations was higher in the SGE-3X group. 

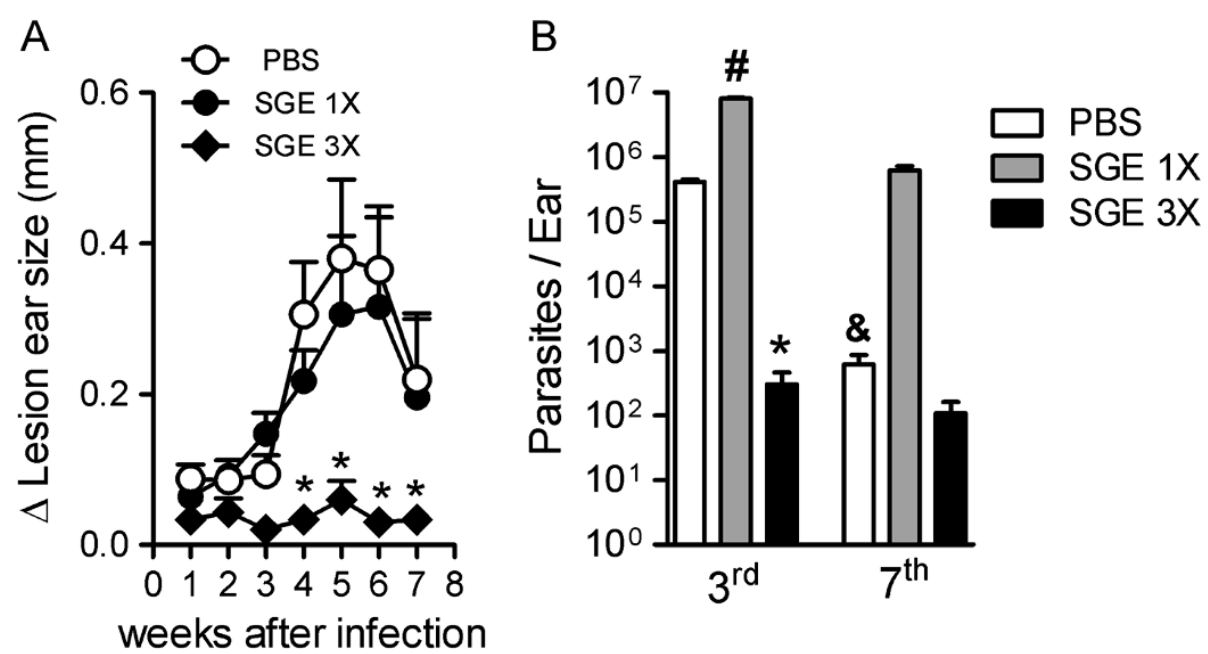

Figure 3 Effect of $L$. longipalpis SGE on the course of $L$. braziliensis infection. BALB/c mice inoculated i.d. once (SGE-1X) or three times (SGE-3X) with Lutzomyia longipalpis SGE or with PBS (control) were challenged with $10^{5} \mathrm{~L}$. braziliensis stationary phase promastigotes forms. The course of infection was monitored weekly by measuring the ear lesion size with a metric caliper. In $\mathbf{A}$, the lesion size was determined by the difference between the infected ear and the opposite uninfected ear given in millimeters $(\mathrm{mm})(\mathrm{n}=5$ mice per group). Data represent the mean \pm SEM and are representative of two independent experiments. ${ }^{\#} P<0.05$ compared with PBS. ${ }^{*} \mathrm{P}<0.05$ compared with the SGE1-X or SGE-3X group. Ear parasitic burden at the 3rd and 7th week post-infection were determined by a limiting-dilution assay (B). The data shown represent the mean \pm SEM of two independent experiments, and each experiment was performed with five mice per group $(n=5) .{ }^{\#} P<0.05$ compared with PBS group. ${ }^{\circledR} P<0.05$ compared with PBS group. ${ }^{*} \mathrm{P}<0.05$ compared with the SGE-1X group.

L. braziliensis infection induced the migration of $\mathrm{CD} 4{ }^{+} \mathrm{FOXP}^{+}$regulatory T cells to the ear lesion (Figure 5G). However, SGE-1X treatment enhanced the number of $\mathrm{CD}^{+}{ }^{+} \mathrm{FOXP3}^{+}$cells by three- to four-fold in the site of infection. Furthermore, in contrast with aforementioned cells, the number of $\mathrm{CD} 4^{+} \mathrm{FOXP}^{+}{ }^{+} \mathrm{T}$ cells was significantly reduced by one- to two-fold in the SGE-3X group.

Our results also shown that, despite of SGE-1X presented the enhancement of neutrophil and macrophage, in the SGE-3X group both cell population was reduced. These reductions were, in average, $47 \%$ to macrophage (Figure $5 \mathrm{H}$ ) and $48 \%$ to neutrophil (Figure $5 \mathrm{I}$ ). These results therefore suggest that different saliva inoculums alters the inflammatory cell and cytokine composition at the site of parasite inoculation, and modulate the immune response during L. braziliensis infection.

\section{The protective effect of saliva is mediated by IFN- $\gamma$ release}

Because SGE-3X treatment protected the mice from parasitic infection (Figure 3) and induced significant production of IFN- $\gamma$ (Figure 4B) by increasing the emigration of $\mathrm{CD}^{+}$ $\mathrm{T}$ cells and $\mathrm{CD}^{+} \mathrm{T}$ cells (Figure 5 ), we further investigated the impact of IFN- $\gamma$ production on resistance against $L$. braziliensis infection.

$\mathrm{BALB} / \mathrm{c}$ mice sensitized with three treatments of saliva (SGE-3X) were depleted of IFN- $\gamma$ by treatment with antiIFN- $\gamma$ mAb (R46A2 clone) and then were challenged with the parasite. As a control group, mice were also treated with a non-relevant IgG antibody.

As shown in Figure 6A, SGE-3X mice treated with IgG control antibody developed minor edema that rapidly decreased with healing skin. Moreover, low parasitic titers were detected in this group (Figure 6B). Conversely, depletion of INF- $\gamma$ reduced the protective effect

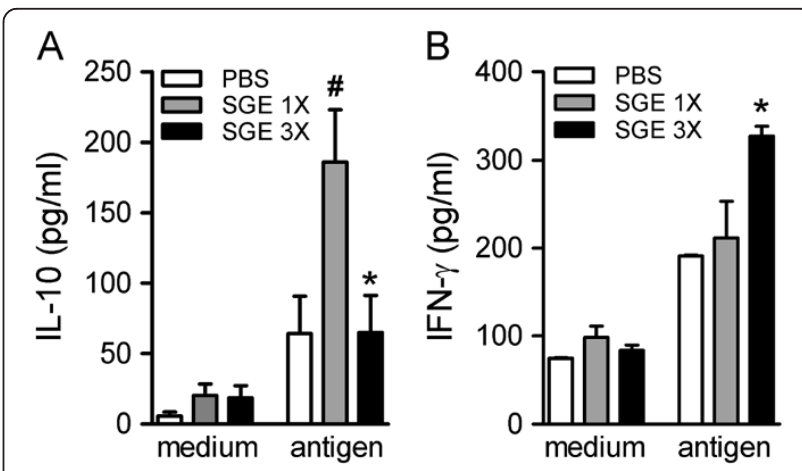

Figure 4 Cytokine production by the draining lymph nodes after different inoculums of SGE. BALB/C mice inoculated i.d. once (SGE-1X) or three times (SGE-3X) with Lutzomyia longipalpis SGE or with PBS (control) were challenged with $10^{5} \mathrm{~L}$. braziliensis stationary phase promastigote forms. At the end of the 7th week postinfection, draining lymph node cells were harvested and restimulated in vitro with $L$. braziliensis antigen $(5 \mu \mathrm{g} / \mathrm{ml})$ or medium for $72 \mathrm{~h}$. IL-10 (A) and IFN- $\gamma$ (B) levels in the supernatant were determined by ELISA assay. The results are expressed as the mean \pm SEM of at least two independent experiments using four to five mice per group ( $n=4-5$ mice per group). ${ }^{\#} P<0.05$ compared with medium-only stimulus. ${ }^{*} P<0.05$ compared with the SGE-1X group. 


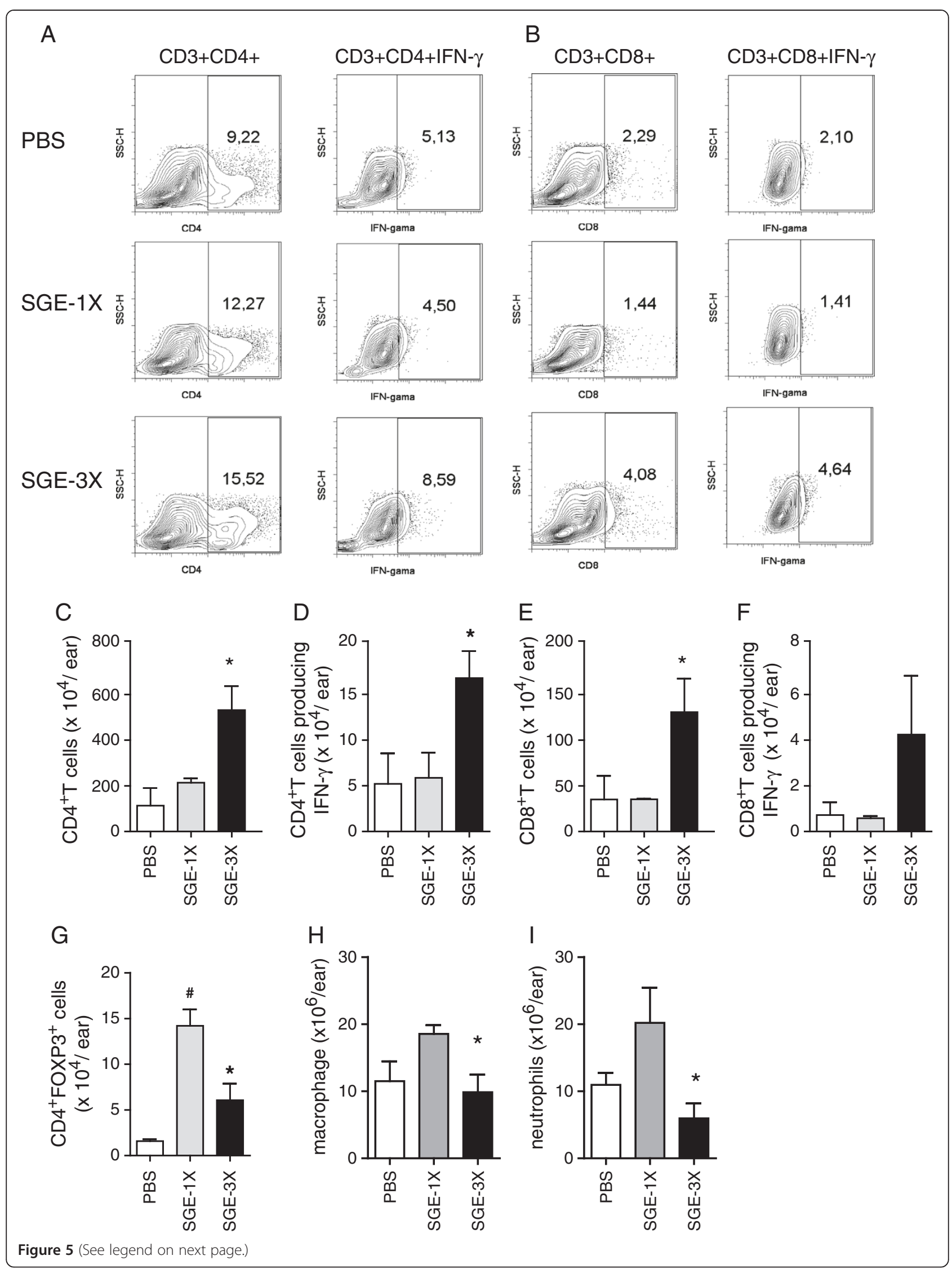


(See figure on previous page.)

Figure $\mathbf{5}$ Inflammatory profile during $L$. braziliensis infection after co-inoculation or pre-sensitization with saliva. BALB/C mice inoculated i.d. once (SGE-1X) or three times (SGE-3X) with Lutzomyia longipalpis SGE or with PBS (control) were challenged with $10^{5}$ L. braziliensis stationary phase promastigote forms. At the end of 7th week post-infection, ears were harvested, processed and inflammatory leucocytes were sorted using specific antibodies. For intracellular cytokines, the cells were in vitro re-stimulated with lived parasites. Dot plots represent the percentages of $C D 4^{+} C D 3^{+}$ and $C D 4^{+} \mathrm{IFN}-\gamma^{+}$cells (A-left panel), $C D 8^{+} \mathrm{CD}^{+}$and $\mathrm{CD} 8^{+} \mathrm{IFN}-\gamma^{+}$cells (B-right panel). Total number of CD4 ${ }^{+} \mathrm{T}$ cells (C) and CD4 $4^{+} \mathrm{IFN}-\gamma^{+}$cells (D) or CD8 ${ }^{+}$ T cells (E) and $\mathrm{CD}^{+}{ }^{+} \mathrm{FN}-\gamma^{+}$cells (F), CD4 ${ }^{+} \mathrm{FOXP3} 3^{+}$cells $(\mathbf{G})$, macrophages $(\mathbf{H})$ and neutrophils (I) within the ears were identified by flow cytometry. Data represent the mean \pm SEM and are representative of two different experiments $(n=4) .{ }^{\#} P<0.05$ compared with PBS. ${ }^{*} P<0.05$ compared with the SGE-1X group.

of saliva on the course of L. braziliensis infection leading to a significant increase in the ear lesion size $(\mathrm{p}<0.05)$ beginning at 3rd week of infection and persisting throughout the period of analysis (Figure 6A). Importantly, $\mathrm{mAb}$ anti-IFN- $\gamma$ treatment also resulted in an increase in parasitic load at the inoculation site.

\section{Discussion}

In this study, we reported that the dual effect of salivary gland extract (SGE) saliva from Lutzomyia longipalpis on the susceptibility or resistance of mice to Leishmania braziliensis infection is characterized by distinct changes in cellular immunity due to coinoculation or pre-exposure

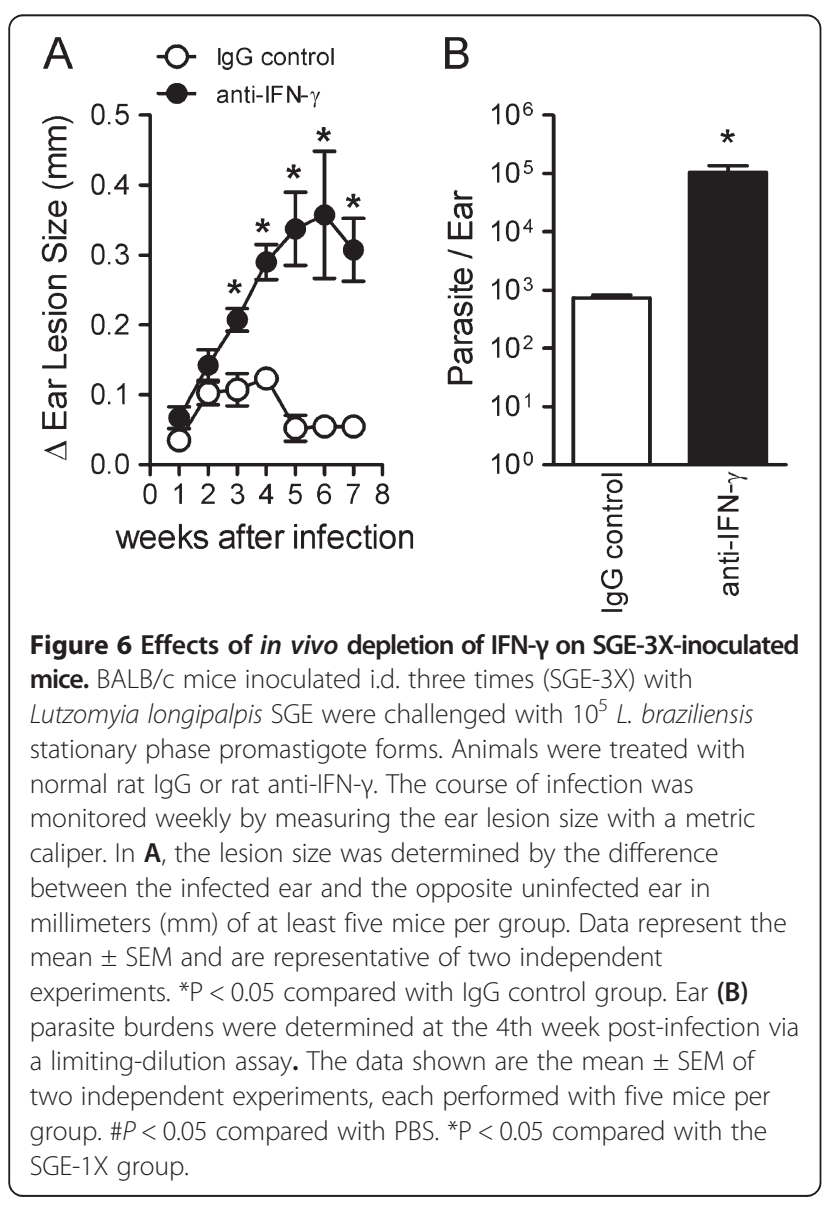

to saliva. Defining the nature of the inflammatory leucocytes that emigrate after saliva injection may help in the understanding of Leishmania infection biology and, therefore, may help in the development of new vaccine approaches that effectively protect the host against parasitic infection.

Studies have reported that immunization of mice with Phlebotomine saliva confers upon the mice a protective phenotype against Leishmania sp., whereas parasite and saliva that is simultaneously co-injected exacerbates infection, suggesting that immune responses triggered by the Phlebotomine saliva could represent a critical step in the development of disease. In this study, we showed that SGE inoculated once (SGE-1X), representing a coinoculation, associated with a marked recruitment of several leucocytes, and most leucocytes were of the macrophage and neutrophil lineage. Interestingly, preexposure to saliva (SGE inoculated three times - SGE-3X) completely changed the cellular infiltrate composition. SGE-3X itself or during infection drastically reduced the amount of neutrophils and macrophages that migrated into the inoculation site even in the absence of parasitic infection, suggesting that the blockage of neutrophils and macrophage recruitment to the inflammatory site by saliva immunization is important to induce immune protection against parasitic infection. In fact, recent studies have described that neutrophils recruited to the site of Leishmania infections internalize the parasite [26,27], and saliva enhances neutrophil migration to the site of infection [28]. Previous studies have also observed that parasite internalization delays the apoptosis of neutrophils and induces MIP- $1 \beta$ release, which recruits macrophages to the site of infection. The migrated macrophages ingest the infected apoptotic neutrophils, which stimulates the release of TGF- $\beta$ and $\mathrm{PGE}_{2}$ and downregulates macrophage activation consequently contributing to Leishmania infection establishment $[26,27]$. Together, these findings suggest that the parasites use granulocytes as "Trojan horses" to attack the macrophages [26]. In this context, the inhibition of both neutrophils and macrophages by saliva preexposure as described in the present investigation may represent an additional mechanism to explain the ability of Phlebotomine saliva pre-inoculation to protect mice against Leishmania infection. 
Stressing the relevance of our finding, we demonstrated for the first time that Phlebotomine saliva increases regulatory $\mathrm{T}$ cell (Treg) recruitment to the lesion site. We demonstrated that inoculation of saliva once (SGE-1X) in the absence of parasites induces the recruitment of high numbers of $\mathrm{CD}^{+} \mathrm{CD} 25^{+}$cells that, although being commonly accepted phenotype of Tregs also could be related to activated cells. Accordingly, parasites co-inoculated with saliva (SGE-1X) caused an increase in the recruitment of $\mathrm{CD} 4^{+} \mathrm{Foxp} 3^{+}$cells to the infection site, suggesting that saliva of L. longipalpis increases Tregs during the infection. Despite the fact that the parasite alone is able to induce Treg migration, saliva strengthens this migration, which maintains the persistence of the parasite in the chronic phase of infection, and suggests that the recruitment of Tregs by the saliva may contribute to the infectivity of Leishmania. In fact, increased numbers of parasites at later time points were observed in the ears of mice co-inoculated with saliva and parasite, which corresponds to the point at which the disease becomes resolved and the parasitic burden decreases in the ears of mice infected with parasite only. Previous studies have also demonstrated that during infection with $L$. major, the persistence of the pathogen within the skin of L. major-resistant mice is controlled by an endogenous population of Treg cells that act to suppress the immune response against $L$. major. Treg cells are involved in maintaining the latency status of Leishmania infections and facilitate the survival of the parasite [29]. Our group reported that $\mathrm{CD} 4{ }^{+} \mathrm{CD} 25^{+} \mathrm{T}$ cells present in skin lesions of patients with cutaneous leishmaniasis display phenotypic and functional characteristics of natural Treg cells [30]. Thus, Treg cells induced by saliva play an important role in modulating the immune response during Leishmania infections. Notably, $\mathrm{CD} 4^{+}$Foxp $3^{+}$cells were at normal levels in the ears of mice pre-sensitized to saliva (SGE-3X), which may have contributed to the control of Leishmania growth.

Our analyses of cytokine production further support the idea that SGE affects the inflammatory cell influx. Interestingly, our data show that in vitro stimulation of draining lymph node cells from SGE-1X mice with parasitic antigens results in higher levels of IL-10, whereas the IL-10 level in SGE-3X-derived draining lymph nodes cell cultures remained unchanged. Whereas the production of IL-10 was unchanged in the SGE-3X mice, IFN- $\gamma$ production increased in the supernatant of SGE-3X lymph node-derived cell cultures, indicating that the inhibition of IL-10 in the SGE-3X mice may have resulted in better control of Leishmania infection. In fact, the severity of disease represented by the lesion size and parasitic burden was not observed in mice pre-sensitized with saliva (SGE-3X).

IL-10 is an anti-inflammatory cytokine produced by several cell types including macrophages, neutrophils and Treg cells, and IL-10 displays diverse immunomodulatory functions [31,32]. In regard to leishmaniasis, IL-10 inhibits cytokine production by T cells (e.g., IL-2), monocytes/macrophages and dendritic cells (e.g., IL- $1 \alpha$ and IL-1 $\beta$, IL-6, IL-8, IL-12, TNF- $\alpha$, and granulocytemacrophage colony-stimulating factor) as well as the production of $\mathrm{NO}$ and $\mathrm{H}_{2} \mathrm{O}_{2}$ ultimately favoring parasitic survival [32,33]. The hypothesis that IL-10 induced by saliva is involved in disease progression during Leishmania infection is supported by a significant enhancement in lesion development and parasitic burden in mice that were co-inoculated with saliva and parasites. The increase in IL-10 production has been reported in treatment with other Phlebotomine saliva sources. In previous studies, we demonstrated that the saliva from the Old World species Phlebotomines $P$. papatasi and P. duboscqi act mainly on dendritic cells and induce the production of IL-10 by a mechanism dependent of $\mathrm{PGE}_{2}$. In turn, $\mathrm{PGE}_{2}$ acts in an autocrine manner to reduce the antigen-presenting ability of DCs [13]. Previous studies have also shown in vitro and in vivo examples of Lutzomyia longipalpis saliva promotes inducing IL-10 production by macrophages and T cells, which exacerbates Leishmania infection [34]. Moreover, the genetic ablation of IL-10 prevents the detrimental effect of SGE on Leishmania major and L. amazonensis infections.

The reduced ability of SGE-3X- inoculated mice to produce IL-10 may be associated with an increase in IFN- $\gamma$ production. Consistently, the depletion of IFN- $\gamma$ using IFN- $\gamma$-neutralizing monoclonal antibody reduced the protective profile of saliva upon Leishmania disease. Despite the significant increase in $\mathrm{CD}^{+} \mathrm{T}$ cells in the ears of mice that were pre-inoculated with saliva three times (SGE-3X), our evidence suggests that CD4 ${ }^{+} \mathrm{T}$ cells and $\mathrm{CD}^{+} \mathrm{T}$ cells contributed to the increased ex vivo production of IFN- $\gamma$ during Leishmania infection. Although the present study is insufficient to declare the mechanism by which the immune cells mediate the control of Leishmania growth, we believe that the presence of lymphocytes producing IFN- $\gamma$ at the site of inflammation may induce the direct killing of L. braziliensis by nitric oxide (NO)-dependent mechanisms. This effect could be mediated by proteins presents into saliva that are uptake by antigen- presenting cells and prime naïve $\mathrm{CD}^{+} \mathrm{T}$ cell and $\mathrm{CD}^{+} \mathrm{T}$ cells. When the mice are challenged with parasite in the presence of saliva, it triggers a rapid $\mathrm{T}$ cells activation and production of IFN- $\gamma$. Thus, there is a cross-reactivity of the immune response induced by salivary proteins against Leishmania braziliensis. This hypothesis has been validated in models with salivary proteins. PpSP15 protein derived from Phlebotomus papatasii provided protective immune response against $L$. major when the parasite was co-inoculated with $P$. papatasi SGE by the induction of DTH response [16]. Likewise, the 
immunization of mice with proteins from Lutzomyia longipalpis, LJM11 and LJM19 induced the strong DTH and conferred the protective effect against different species of Leishmania (L. major, L. infantum and L. braziliensis) when the mice were challenged with parasite and SGE [35-39]. Interestingly, such responses were similar with that previously obtained using a natural sensitization with bites of uninfected sand fly [15].

Several pieces of evidence have shown that Phlebotomine saliva enhances the infectivity of many different Leishmania species, which can be attributed to numerous substances within the saliva that harbor pharmacological properties that induce vasodilatation, anticoagulation, antiinflammation and immunomodulation. Thus, the active salivary constituents could serve as a prototype for the development of vaccines to control pathogen transmission. Our group is currently working on the isolation of compounds within the saliva of several blood-feeding arthropods, including Phlebotomine vectors. We recently identified adenosine (ADO) and adenosine monophosphate (AMP) as major immunomodulatory compounds present within the Old World sand fly species Phlebotomus papatasii, which protected mice from extreme inflammatory insults [40]. Salivary protein (SP)-15 is also present in P. papatasi, and SP-15 provides a protective effect against

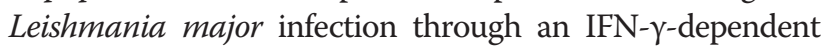
mechanism [16]. In the present study, neither ADO and AMP nor SP-15 is involved in the effect of SGE on Leishmania infection because they are not found in Lutzomyia longipalpis saliva. Maxadilan (MAX) is a potent vasodilator present in L. longipalpis saliva that exacerbates Leishmania $s p$. infection. Mice vaccinated with recombinant MAX were markedly protected from Leishmania infection, and this protective effect was associated with an increase in $\mathrm{CD}^{+}{ }^{+} \mathrm{T}$ cells, IFN- $\gamma$ and NO [14]. Presently, we cannot dismiss the possibility that the protective effect of SGE$3 \mathrm{X}$ could be mediated by MAX; however, several other proteins (LJM17 and LJM11 in human and LJM17, LJM11, LJL13, LJL23 and LJL143 in dogs) from $L$. longipalpis saliva have been identified [41], suggesting that intensive efforts are required for the identification of salivary compounds responsible for the protective effect of sand fly saliva on leishmaniasis.

\section{Conclusion}

In summary, the present study provides strong evidence that different Lutzomyia longipalpis saliva inoculation schemes may skew the initial cellular responses, which is reflected by parasitic survival or host resistance to infection. Thus, we believe that comprehending the effects of sand fly saliva on the host immune response induced by saliva may help in the generation of new vaccine strategies that can block the effects of saliva and prevent Leishmania establishment in the host.

\section{Abbreviations}

SGE-1X: Salivary gland extract inoculated once; SGE-3X: Salivary gland extract inoculated three times.

\section{Competing interest}

The authors declare that they have no competing interest.

\section{Author contributions}

Conceived and designed the experiments: VC and JSS. Performed the experiments: VC and DLC. Analyzed the data: VC and JSS. Contributed reagents/materials/analysis tools: $\mathrm{CIB}, \mathrm{AMB}, \mathrm{MB}, \mathrm{FQC}$ and JSS. Wrote the paper: VC and JSS. Revised the paper DLC, CIB, AMB, MB and FQC. All authors read and approved the final manuscript.

\section{Acknowledgements}

We are thankful to FAPESP, CAPES, CNPq, INCTV and FAEPA for their financial support.

\section{Author details}

'Department of Biochemistry and Immunology, School of Medicine of Ribeirão Preto, University of São Paulo, Av Bandeirantes, 3900. Ribeirão Preto, São Paulo, Brazil. ²Department of Pharmacology, School of Medicine of Ribeirão Preto, University of São Paulo, São Paulo, Brazil. ${ }^{3}$ Centro de Pesquisa Gonçalo Muniz, Fundação Oswaldo Cruz (FIOCRUZ), São Paulo, Brazil. ${ }^{4}$ School of Medicine, Federal University of Bahia, Salvador, Brazil. ${ }^{5}$ Institute of Immunological Research, Salvador, Brazil.

Received: 8 January 2013 Accepted: 4 May 2013

Published: 8 May 2013

\section{References}

1. Beach R, Kiilu G, Leeuwenburg J: Modification of sand fly biting behavior by Leishmania leads to increased parasite transmission. AmJTrop Med Hyg 1985, 34(2):278-282.

2. Ribeiro JM: Role of saliva in blood-feeding by arthropods. Annu Rev Entomol 1987, 32:463-478.

3. Titus RG, Ribeiro JM: The role of vector saliva in transmission of arthropod-borne disease. Parasitol Today 1990, 6(5):157-160.

4. Ribeiro JM: Blood-feeding arthropods: live syringes or invertebrate pharmacologists? Infect Agents Dis 1995, 4(3):143-152.

5. Waitumbi J, Warburg A: Phlebotomus papatasi saliva inhibits protein phosphatase activity and nitric oxide production by murine macrophages. Infect Immun 1998, 66(4):1534-1537.

6. Titus RG, Bishop JV, Mejia JS: The immunomodulatory factors of arthropod saliva and the potential for these factors to serve as vaccine targets to prevent pathogen transmission. Parasite Immunol 2006, 28(4):131-141.

7. Lima HC, Titus RG: Effects of sand fly vector saliva on development of cutaneous lesions and the immune response to Leishmania braziliensis in BALB/c mice. Infect Immun 1996, 64(12):5442-5445.

8. Mbow ML, Bleyenberg JA, Hall LR, Titus RG: Phlebotomus papatasi sand fly salivary gland lysate down-regulates a Th1, but up-regulates a Th2, response in mice infected with Leishmania major. J Immunol 1998 , 161(10):5571-5577.

9. Belkaid Y, Kamhawi S, Modi G, Valenzuela J, Noben-Trauth N, Rowton E, Ribeiro J, Sacks DL: Development of a natural model of cutaneous leishmaniasis: powerful effects of vector saliva and saliva preexposure on the long-term outcome of Leishmania major infection in the mouse ear dermis. J Exp Med 1998, 188(10):1941-1953.

10. Scott $P$, Artis D, Uzonna J, Zaph C: The development of effector and memory T cells in cutaneous leishmaniasis: the implications for vaccine development. Immunol Rev 2004, 201:318-338.

11. Sacks D, Anderson C: Re-examination of the immunosuppressive mechanisms mediating non-cure of Leishmania infection in mice. Immunol Rev 2004, 201:225-238.

12. De Freitas LA, Mbow LM, Estay M, Bleyenberg JA, Titus RG: Indomethacin treatment slows disease progression and enhances a Th1 response in susceptible BALB/c mice infected with Leishmania major. Parasite Immunol 1999, 21(5):273-277.

13. Carregaro V, Valenzuela JG, Cunha TM, Verri WA Jr, Grespan R, Matsumura G, Ribeiro JM, Elnaiem DE, Silva JS, Cunha FQ: Phlebotomine salivas inhibit immune inflammation-induced neutrophil migration via an autocrine 
DC-derived PGE2/IL-10 sequential pathway. J Leukoc Bio/ 2008, 84(1):104-114

14. Morris RV, Shoemaker CB, David JR, Lanzaro GC, Titus RG: Sandfly maxadilan exacerbates infection with Leishmania major and vaccinating against it protects against L. major infection. J Immunol 2001, 167(9):5226-5230.

15. Kamhawi S, Belkaid Y, Modi G, Rowton E, Sacks D: Protection against cutaneous leishmaniasis resulting from bites of uninfected sand flies. Science 2000, 290(5495):1351-1354.

16. Valenzuela JG, Belkaid Y, Garfield MK, Mendez S, Kamhawi S, Rowton ED, Sacks DL, Ribeiro JM: Toward a defined anti-Leishmania vaccine targeting vector antigens: characterization of a protective salivary protein. J Exp Med 2001, 194(3):331-342.

17. Monteiro MC, Lima HC, Souza AA, Titus RG, Romão PR, Cunha FQ: Effect of Lutzomyia longipalpis salivary gland extracts on leukocyte migration induced by Leishmania major. AmJTrop Med Hyg 2007, 76(1):88-94

18. Teixeira CR, Teixeira MJ, Gomes RB, Santos CS, Andrade BB, Raffaele-Netto I, Silva JS, Guglielmotti A, Miranda JC, Barral A, Brodskyn C, Barral-Netto M: Saliva from Lutzomyia longipalpis induces $\mathrm{CC}$ chemokine ligand 2/monocyte chemoattractant protein-1 expression and macrophage recruitment. J Immunol 2005, 175(12):8346-8353.

19. Maurer M, Dondji B, von Stebut E: What determines the success or failure of intracellular cutaneous parasites? Lessons learned from leishmaniasis. Med Microbiol Immunol 2009, 198(3):137-146.

20. Anjili CO, Mbati PA, Mwangi RW, Githure Jl, Olobo JO, Robert LL, Koech DK The chemotactic effect of Phlebotomus duboscqi (Diptera: Psychodidae) salivary gland lysates to murine monocytes. Acta Trop 1995, 60(2):97-100.

21. Zer R, Yaroslavski I, Rosen L, Warburg A: Effect of sand fly saliva on Leishmania uptake by murine macrophages. Int J Parasitol 2001, 31(8):810-814

22. Peters NC, Sacks DL: The impact of vector-mediated neutrophil recruitment on cutaneous leishmaniasis. Cell Microbiol 2009, 11(9):1290-1296.

23. Titus RG, Ribeiro JM: Salivary gland lysates from the sand fly Lutzomyia longipalpis enhance Leishmania infectivity. Science 1988, 239(4845):1306-1308.

24. Costa DL, Carregaro V, Lima-Júnior DS, Silva NM, Milanezi CM, Cardoso CR, Giudice Â, de Jesus AR, Carvalho EM, Almeida RP, Silva JS: BALB/c mice infected with antimony treatment refractory isolate of Leishmania braziliensis present severe lesions due to IL-4 production. PLoS Negl Trop Dis 2011, 5(3):e965.

25. Mckinney MM, Parkinson A: A simple, non-chromatographic procedure to purify immunoglobulins from serum and ascites fluid. I Immunol Methods 1987, 96(2):271-278.

26. van Zandbergen G, Klinger M, Mueller A, Dannenberg S, Gebert A, Solbach W, Laskay T: Cutting edge: neutrophil granulocyte serves as a vector for Leishmania entry into macrophages. J Immunol 2004, 173(11):6521-6525.

27. Ribeiro-Gomes FL, Otero AC, Gomes NA, Moniz-De-Souza MC, CysneFinkelstein L, Arnholdt AC, Calich VL, Coutinho SG, Lopes MF, DosReis GA: Macrophage interactions with neutrophils regulate Leishmania major infection. J Immunol 2004, 172(7):4454-4462

28. Peters NC, Egen JG, Secundino N, Debrabant A, Kimblin N, Kamhawi S, Lawyer P, Fay MP, Germain RN, Sacks D: In vivo imaging reveals an essential role for neutrophils in leishmaniasis transmitted by sand flies. Science 2008, 321(5891):970-974.

29. Belkaid Y, Rouse BT: Natural regulatory T cells in infectious disease. Nat Immunol 2005, 6(4):353-360.

30. Campanelli AP, Roselino AM, Cavassani KA, Pereira MS, Mortara RA, Brodskyn Cl, Goncalves HS, Belkaid Y, Barral-Netto M, Barral A, Silva JS: CD4 + CD25+ $T$ cells in skin lesions of patients with cutaneous leishmaniasis exhibit phenotypic and functional characteristics of natural regulatory T cells. $J$ Infect Dis 2006, 193(9):1313-1322.

31. Sabat R: IL-10 family of cytokines. Cytokine Growth Factor Rev 2010, 21(5):315-324

32. Moore KW, de Waal MR, Coffman RL, O'Garra A: Interleukin-10 and the interleukin-10 receptor. Annu Rev Immunol 2001, 19:683-765.

33. Ding Y, Chen D, Tarcsafalvi A, Su R, Qin L, Bromberg JS: Suppressor of cytokine signaling 1 inhibits IL-10-mediated immune responses. J Immunol 2003, 170(3):1383-1391.
34. Norsworthy NB, Sun J, Elnaiem D, Lanzaro G, Soong L: Sand fly saliva enhances Leishmania amazonensis infection by modulating interleukin10 production. Infect Immun 2004, 72(3):1240-1247.

35. Gomes R, Teixeira C, Teixeira MJ, Oliveira F, Menezes MJ, Silva C, de Oliveira Cl, Miranda JC, Elnaiem DE, Kamhawi S, Valenzuela JG, Brodskyn Cl: Immunity to a salivary protein of a sand fly vector protects against the fatal outcome of visceral leishmaniasis in a hamster model. Proc Natl Acad Sci U S A 2008, 105(22):7845-7850

36. Xu X, Oliveira F, Chang BW, Collin N, Gomes R, Teixeira C, Reynoso D, My Pham V. Elnaiem DE, Kamhawi S, Ribeiro JM, Valenzuela JG, Andersen JF: Structure and function of a "yellow" protein from saliva of the sand fly Lutzomyia longipalpis that confers protective immunity against Leishmania major infection. J Biol Chem 2011, 286(37):32383-32393.

37. da Silva RA, Tavares NM, Costa D, Pitombo M, Barbosa L, Fukutani K, Miranda JC, de Oliveira Cl, Valenzuela JG, Barral A, Soto M, Barral-Netto M, Brodskyn C: DNA vaccination with KMP11 and Lutzomyia longipalpis salivary protein protects hamsters against visceral leishmaniasis. Acta Trop 2011, 120(3):185-190.

38. Tavares NM, Silva RA, Costa DJ, Pitombo MA, Fukutani KF, Miranda JC, Valenzuela JG, Barral A, de Oliveira Cl, Barral-Netto M, Brodskyn C: Lutzomyia longipalpis saliva or salivary protein LMM19 protects against Leishmania braziliensis and the saliva of its vector, Lutzomyia intermedia. PLoS Negl Trop Dis 2011, 5(5):e1 169.

39. Gomes R, Oliveira F: The immune response to sand fly salivary proteins and its influence on leishmania immunity. Front Immunol 2012, 3:110.

40. Carregaro V, Sá-Nunes A, Cunha TM, Grespan R, Oliveira CJ, Lima-Junior DS, Costa DL, Verri WA Jr, Milanezi CM, Pham VM, Brand DD, Valenzuela JG, Silva JS, Ribeiro JM, Cunha FQ: Nucleosides from Phlebotomus papatasi salivary gland ameliorate murine collagen-induced arthritis by impairing dendritic cell functions. J Immunol 2011, 187(8):4347-4359.

41. Teixeira C, Gomes R, Collin N, Reynoso D, Jochim R, Oliveira F, Seitz A, Elnaiem DE, Caldas A, de Souza AP, Brodskyn Cl, de Oliveira Cl, Mendonca I, Costa CH, Volf P, Barral A, Kamhawi S, Valenzuela JG: Discovery of markers of exposure specific to bites of Lutzomyia longipalpis: the vector of Leishmania infantum chagasi in Latin America. PLoS Negl Trop Dis 2010, 4(3):e638.

\section{doi:10.1186/1471-2180-13-102}

Cite this article as: Carregaro et al:: Dual effect of Lutzomyia longipalpis saliva on Leishmania braziliensis infection is mediated by distinct salivainduced cellular recruitment into BALB/C mice ear. BMC Microbiology 2013 13:102.

\section{Submit your next manuscript to BioMed Central and take full advantage of:}

- Convenient online submission

- Thorough peer review

- No space constraints or color figure charges

- Immediate publication on acceptance

- Inclusion in PubMed, CAS, Scopus and Google Scholar

- Research which is freely available for redistribution 